\title{
O LANÇAMENTO DA LÁPI\& DE OURO ou Dona Flor e seus dois maridos chega a Feira de Santana
}

\section{Benedito Veiga}

A posição geográfica de Feira de Santana, a meio caminho entre a costa e o interior, reflete-se na economia do município.

(Poppino, 1968, 17)

O consumo de louça de barro chegou a ser tão difundido entre a população que na antiga feira livre - que às segundasfeiras ocupava quase todo o centro da cidade - havia um local denominado de "feira das panelas", onde podiam ser encontrados comerciantes dos mais diversos tipos de utensílios cerâmicos e, principalmente, as louceiras da região.

(Dórea, 2004, 102)

Antes de quaisquer outros esclarecimentos, dois deles se fazem importantes para a compreensão do lançamento da Livraria Lápis de Ouro - o lançamento da Lápis de Ouro, acontecido na Praça da Bandeira, em Feira de Santana, no dia 21 de julho de 1966, das 17 às 19 horas. É o primeiro lançamento ocorrido, no ano da estréia da narrativa Dona Flor e seus Dois Maridos, de Jorge Amado, fora de capitais dos estados brasileiros, ao que os documentos coletados em periódicos indicam, e, no meu entender, é um dos desdobramentos do primeiro lançamento da Livraria Civilização Brasileira, com sede à Rua d'Ajuda - o lançamento d'Ajuda, o inaugural em terras baianas, anteriormente verificado em Salvador.

No aspecto inicial, destaca-se o papel desempenhado por Feira de Santana, enquanto município baiano, sede do mais saliente entroncamento rodoviário do Norte / Nordeste, com um pólo cultural, inclusive com artistas de destaque no cenário nacional / local, como são exemplos: o plástico Raimundo Oliveira, o cineasta Ruy Santos, e os literatos Godofredo Filho e Eurico Alves. No aspecto seguinte, a imprensa estadual tinha representantes da comunidade feirense, com colunas semanais em órgãos jornalísticos considerados, como é o caso de "Informes de Antônio José", no Diário de Notícias, sob a rubrica de Antônio Laranjeiras. 
O lançamento da Lápis de Ouro, realizado na extinta livraria homônima - talvez, o mais importante ponto do comércio livreiro existente na praça - desperta a curiosidade do público feirense, além de transpor lembranças das idéias da chegada de Dona Flor, com sua estréia no dia $1^{\circ}$ de julho do mesmo ano, no emblemático lançamento d'Ajuda.

Os preparativos e as repercussões desse evento acontecem e ressoam além fronteiras locais, sendo o fato noticiado também na capital baiana, como atesta uma dezena de notícias divulgadas no Diário de Notícias e no Jornal da Babia, periódicos sediados em Salvador, e na Folha do Norte, destacado veículo da mídia impressa existente na Princesa do Sertão.

Atendendo objetivos do levantamento da memória cultural da região, foram ouvidos membros da comunidade que presenciaram o acontecimento, o que serviu para limpeza e ampliação dos dados registrados nos documentos existentes.

Feira de Santana dista cerca de $108 \mathrm{Km}$ de Salvador e o município está localizado na Região do Paraguaçu, uma das mais bonitas do estado, com excelente potencial turístico, com muitos atrativos naturais, como serras, cachoeiras, rios e grutas, formando cenários privilegiados para o convívio e a reflexão. O clima dominante é o semiárido. Sua produção agrícola é centrada na mandioca, no feijão, no milho, no sisal, na mamona. Dentre seus rebanhos, destacam-se o bovino, o caprino e o ovino.

Segundo os informes do Instituto Baiano de Expansão Cultural, que traça um perfil dos municípios baianos em 1974, a Vila de Santana foi criada pelo Decreto de 13 de novembro de 1832, tornando-se cidade pela Lei Provincial número 1320, de 16 de junho de 1873. A denominação de Feira foi dada pelo Decreto número 7479, de 8 de julho de 1931.

São limites do Município: ao Norte, Tanquinho, Santa Bárbara e Santanópolis, ao Sul, Antônio Cardoso, São Gonçalo dos Campos e Santo Amaro, ao Leste, Santanópolis, Coração de Maria e Jacuípe, e a Oeste, Anguera, Serra Preta e Antônio Cardoso. (IBEC, 1974)

Até bem pouco tempo antes do lançamento, Feira de Santana era uma cidade de costumes tipicamente sertanejos. Destacava-se seu comércio de gado, um dos mais importantes do país. Quando da chegada de Dona Flor, era o quarto município baiano, enquanto sua sede ocupava o segundo posto, vindo logo após a Capital, com uma população próxima dos 150.000 habitantes. Tal importância era devida à combinação de fatores geográficos e humanos, como escreve Rollie Poppino: "A população crescente no município exige um consumo local cada vez pronunciado de gado e de pro- 
dutos agrícolas, enquanto a proximidade das cidades costeiras assegura aos criadores um mercado imediato para os excedentes." (Poppino, 1968, 11)

Pouco antes desse evento, a cidade passou a enveredar no campo industrial, mudando completamente o seu comportamento, o seu sistema de vida, isto é, substituindo um pequeno grupo que controlava seu grande comércio de gado por jovens e dinâmicos executivos, à frente de suas indústrias e de empreendimentos, responsáveis pelo progresso vertiginoso da cidade.

Seguindo o raciocínio de Mario Padre, em Através do Brasil,

A sua grande feira livre (às segundas-feiras), que se estendia da praça central da cidade às suas largas e longas avenidas, teve que ser transferida de local, pois com o seu explosivo crescimento sérios problemas estavam sendo criados, embora a feira fosse uma grande atração turística. (Padre, 1979, 12)

Para abrigar a grande feira, foi construído um grande centro de abastecimento em local mais adequado, enquanto que o velho mercado - centro da feira - permanece na praça e será transformado em mercado de arte popular, depois de passar por grande reforma.

A cidade é muito simpática, com as suas ruas largas e extensas avenidas bem movimentadas. Como principal atração turística apresenta sua micareta, a maior e a mais animada de todo o país (não tem carnaval em Feira de Santana), quando, então, se repetia o desfile das mais destacadas fantasias do último carnaval do Rio de Janeiro. Além da micareta, a festa da padroeira N. S. Santana, na segunda quinzena do mês de janeiro, atrai muitos visitantes, que vão assistir à lavagem da igreja, lavagem da lenha, retretas no coreto, às suas novenas bem concorridas e, finalmente, à missa como ponto final da grande festa.

As notícias de Feira de Santana ecoam facilmente em Salvador, não apenas por sua proximidade como ainda por ser o segundo pólo de atração de investimentos do estado, e desenvolver atividades culturais de importância.

Seguindo os contornos do lançamento inicial na "Cidade da Bahia", como prefere chamar a Cidade do Salvador da Baía de Todos os Santos o povo da terra, e Jorge Amado assim endossa em sua obra, o envolvimento demasiado com o hibridismo local e citadino é considerado. Principalmente, quando a própria natureza do texto fictício é questionada e o leitor não se sente espectador, mas um dos participantes dos fatos narrados: todos opinam da exclusão ou do acréscimo de cenas e de personagens incluídos ou não no livro. O lançamento d'Ajuda é, como se fosse, o oruncó da heroína 
amadiana, ou seja, o momento do dia em que a iaô (a noviça, a inicianda) fala, dando nome a seu orixá.

Feira de Santana é, por sua vez, uma urbe mesclada de coloridos étnicos diversos: a população dessa área interiorana é constituída, em grande parte, de sangue índio e europeu, diferentemente da área costeira, onde predominam o negro e o miscigenado deste com o branco.

A construção, o acontecimento e as conseqüências do lançamento d'Ajuda mostram como o clima e as cores de Salvador foram utilizados, ao lado de recursos performáticos, publicitários e mercadológicos, para fazerem do evento o único, o irrepetível, o maior, o mais importante de todos. Posso dizer que, com o lançamento d'Ajuda, é como se houvesse uma rediscussão da função da arte: o escritor, um relator privilegiado de seu tempo, com condições de captar e transmitir aquilo que todos estão sentindo, sem conseguirem, contudo, materializar em discurso ou obra; o escritor capta uma série de informações que estão no ar, codifica tais dados em mensagem para o público. Talvez, em busca de uma escrita centrada em seu lócus, mas também na contemporaneidade de um tempo da eletrônica, da aldeia mcluhaniana, das imagens efêmeras: trocar experiências, arranjando bits de informação.

Do ponto de vista de Renato Cohen - estudioso brasileiro preocupado em ampliar os limites do teatro, absorvendo a contracultura e a performance - em seu livro Performance como linguagem, essa perspectiva adotada pelo autor "[...] não implica limitação, mas, sim, transformação através de outros canais”. (Cohen, 1989, 87)

$\mathrm{Na}$ leitura desse evento, relacionado à recepção local de Dona Flor, não se pode ser surpreendido pelos parâmetros do leitor que esquece - ou não considera -, com suas novas aquisições, suas miúdas metamorfoses e suas estranhas corrupções, o que modifica o meramente transplantado e impõem a assinatura híbrida, como medita e redige Silviano Santiago, em Uma Literatura nos Trópicos, avaliando o ritual antropófago da literatura latino-americana:

A maior contribuição da América Latina para a cultura ocidental vem da destruição sistemática dos conceitos de unidade e de pureza: estes dois conceitos perdem o contorno exato de seu significado, perdem seu peso esmagador, seu sinal de superioridade cultural, à medida que o trabalho de contaminação dos latino-americanos se afirma, se mostra mais e mais eficaz. (Santiago, 2000, 16)

Essa introdução justifica-se porque o lançamento da Lápis de Ouro, como similarmente o lançamento d'Ajuda, faz Jorge Amado se apresentar em sua plenitude de cria- 
dor, de intérprete e de articulador - em todos os liames possíveis: artísticos, publicitários, comerciais - de sua própria obra. Mostra, entreabertas, as portas de sua oficina e, escancaradas, as portas de saída ao encontro dos costumes, de sua gente.

Os lançamentos de Dona Flor obedecem ao encadear divulgado, sobretudo, pela mídia impressa, como, por exemplo, a Tribuna da Imprensa, do Estado da Guanabara, em 19 de maio de 1966: "Calendário de lançamento do importante livro de Jorge Amado, Dona Flor e seus Dois Maridos. Dia 15 de junho: lançamento em São Paulo. Dia 17: Guanabara. Dia $1^{\circ}$ de julho: Salvador". (Fernandes, Tribuna da Imprensa - Rio de Janeiro, 19 maio 1966).

Esses três lançamentos maiores têm mais ampla divulgação, inclusive para a imprensa do Sul do País. Nos registros de documentos em periódicos, verifico outros lançamentos menores, com repercussão mais regional. Um deles, o ocorrido no Estado da Guanabara, foi anterior ao lançamento d'Ajuda, em 21 de junho, como noticia o Correio da Manhã do mesmo dia, convidando, em nome da União Brasileira de Escritores, seção Guanabara (Rio de Janeiro), para o coquetel e noite de autógrafos, no Berro D’Água (Panorama Palace Hotel), nesse mesmo dia, a partir das 18 h, com que homenageia Jorge Amado, pelo lançamento do seu novo romance Dona Flor e seus dois maridos". (Condé, Correio da Manhã - Rio de Janeiro, 21 jun. 1966) Os outros dois, que foram acontecidos em Salvador, são posteriores ao lançamento d'Ajuda: o do dia 14 de julho, quando $A$ Tarde de 13 de julho anuncia que a Livraria Civilização Brasileira vai comemorar o transcurso do primeiro aniversário de suas novas instalações, na Ajuda: "O acontecimento será assinalado com uma tarde de autógrafos, com a participação, dentre outros, dos escritores Jorge Amado, Wilson Lins, Sônia Coutinho, Ariovaldo Matos, Luiz Henrique, Walter da Silveira e Walfrido Morais". (Silveira, A Tarde Salvador, 13 jul. 1966) O outro foi realizado em 29 de julho, como noticia $A$ Tarde do dia 28, do mesmo mês: "Amanhã, às 20 horas, Jorge Amado estará autografando o seu livro Dona Flor e seus dois maridos, na Livraria Pindorama, Av. Sete". (Juli, A Tarde Salvador, 28 jul. 1966)

Na obediência da seqüência divulgada, o lançamento da Lápis de Ouro é o sexto da série (antes do terceiro de Salvador), tendo sua divulgação a partir do Diário de Notícias, de 15 de julho de 1966: "Enquanto isso, no dia 21 vindouro, quinta-feira, Jorge Amado estará realizando, em Feira de Santana, uma tarde de autógrafos de "D. Flor e seus dois maridos", a convite de diversas entidades culturais da "Princesa do Sertão". (Notícia de redação, Diário de Notícias - Salvador, 15 jul. 1966)

A primeira notícia assinada sobre o tema aparece sob o enfoque do jornalista feirense Antônio José, no Diário de Notícias, de 16 de julho de 1966: 
Feira, 21 - Jorge \& "D. Flor"

Feira de Santana - Finalmente a 21 deste, "tout", caminhos intelectuais feirenses convergirão para a Livraria Lápis d'Ouro, para a sensacional tarde de autógrafos do MAGNO Jorge Amado, lançando o comentado romance "D. Flor e seus dois Maridos", graças à ação promocional do crítico literário Dival Pitombo (o "Juiz de Pilão Arcado" - Vide "D. Flor e seus dois Maridos"). (Antônio José, Diário de Notícias Salvador, 16 jul. 1966)

Eram costumeiras as divulgações de acontecimentos sociais por intermédio dos periódicos, com destaque para o desempenho de profissionais da imprensa, muitas vezes à procura de um estilo próprio que chamasse a atenção dos leitores. As colunas desenvolviam uma tarefa híbrida, mesclando notícias de fatos culturais, econômicos e políticos.

Curioso é que o colunista sente-se como que desobrigado por essa notícia, como se fosse mais uma missão cumprida:

Que alívio Feira Cultural sente em ter assegurada a tão sonhada TARDE DE/ do Jorge! Ah! que ansiedade que chegue 21, o DIA - D, quando a Feira, inteligência \& alta roda, além de "tout" patrícios estarão recebendo do expoente máximo da Literatura Nacional, Jorge AMADO, Amado, amado por todos. (Antônio José, Diário de Notícias - Salvador, 16 jul. 1966)

Noto a preocupação de fazer o leitor acreditar que o assunto divulgado vai atingir toda a sociedade interessada, envolvendo os "patrícios": "inteligência \& alta roda”, ou sejam os setores culturais e os de comércio.

Ao encerrar sua nota inicial, Antônio José firma patente com os ditames do "papa" do colunismo local, Sylvio Lamenha, dando amostra de bem informado e fazedor de opinião: "EM TEMPO: Me perdoem, confrades meus, pelo 'snob furo"”. (Antônio José, Diário de Notícias - Salvador, 16 jul. 1966)

Percebo, na idéia do repórter feirense, a vontade de mostrar-se consciente das normas do colunismo da época, pautadas nos procedimentos costumeiros de Ibrahim Sued.

No dia 20 de julho, o Diário de Notícias, em noticiário de redação, lembraria que

Estará seguindo amanhã, para Feira de Santana, uma caravana de jornalistas e intelectuais da Capital, em companhia do romancista Jorge Amado, que reunirá, naquela cidade, seus admiradores e o povo em geral, para uma tarde de autógrafos, com que lançará, ali, o seu mais novo livro "Dona Flor e Seus Dois Maridos". (Notícia de redação, Diário de Notícias - Salvador, 20 jul. 1966). 
A notícia ganha foros de destaque não apenas pela importância do periódico, considerado o mais em evidência em Salvador, integrando os "Diários Associados", sob o comando nacional de Assis Chateaubriand.

Nesse mesmo periódico, na comentada coluna HI-SO, de Sylvio Lamenha, o fato ganharia repercussão: "Amanhã (21), Em Feira de Santana, Jorge AMADO estará autografando 'D. Flor e seus dois maridos', o que está monopolizando as atenções da interiorana e progressista urbs". (Lamenha, Diário de Notícias - Salvador, 20 jul. 1966)

Além de registrar o envolvimento da comunidade citadina, a notícia faz repercutir o próximo evento livreiro de Feira de Santana em todo o Estado da Bahia.

Complementando seus informes, o colunista cita procedimento - já anteriormente adotado no primeiro lançamento da capital - o de o escritor fazer-se acompanhar de personalidades de vários campos culturais: "Com o grande JORGE seguirão também alguns escritores, livreiros, jornalistas, artistas, como Dermeval [sic] Chaves, Luís Henrique, Emanoel [sic] Araújo, Guido Guerra”. (Lamenha, Diário de Notícias Salvador, 20 jul. 1966).

Fazendo parte da campanha publicitária de Dona Flor, seu autor, nos diversos locais de lançamento, costumava estar acompanhado de comitivas representativas da intelectualidade, de representantes do comércio de livros e das chamadas "personalidades" que, de certa forma, foram usadas na narrativa para composição das personagens, presenças, por vezes, marcantes, como acontece também nas proximidades da área da região feirense; são exemplos: "[...] E concluiu [a respeito da conturbada autoria da Elegia à definitiva morte de Vadinho] com o mesmo sorriso e com as mesmas palavras de outrora: - Velho sem-vergonha... [...] Na capa, em letras cavadas na madeira, o nome do poeta: Godofredo Filho.” (Amado, 1997, 31); “[...] os Marinho Falcão, de Feira de Sant'Ana, em cujo armazém Gil [pai de Dona Flor] fizera seu aprendizado quando jovem - fora seu JOÃO MARINHO quem lhe emprestara dinheiro para iniciar-se na capital;" (Amado, 1997, 46); "Certa vez Rosália [irmã mais velha de Dona Flor] para uma dancinha no aniversário da menina mais velha do DR. JOÃo FALCÃO, um graúdo: palacete, lustres de cristal, talheres de prata, garçons a rigor. Os outros convivas tudo gente fina, podre de rica, da melhor sociedade, uma lordeza, só vendo." (Amado, 1997, 51-52); "Quem mais viciado no jogo e na cachaça do que o Doutor Cícero Araújo, um de Santo Amaro da Purificação? A pobre esposa, DONA Pequena, sofria as pena do inferno. Um dia ela pegou barriga e nem o menino nascera, já DOUTOR Cícero virara o cidadão mais exemplar.” (Amado, 1997, 123); “[...] o notário dedicava-se às mulheres, ao seu estudo e conhecimento (se possível, íntimo), le- 
vando o juiz de direito de Pilão Arcado, Doutor Dival Pitombo, a classificá-lo como emérito psicólogo, arguto confidente da alma feminina [...]”.(Amado, 1997, 227).

Tal procedimento, tomando em conta a quantidade e o prestígio das "personalidades" locais, será usado mais uma vez, como registra o Diário de Notícias, de 21 de julho de 1966: "Hoje, em Feira de Santana, Jorge Amado estará autografando seu besseller [sic] 'D. Flor e seus dois maridos', ao lado de uma caravana de intelectuais". (Lamenha, Diário de Notícias - Salvador, 21 jul. 1966).

O Jornal da Babia, de 20 de julho, confirma, por igual, componentes dessa comitiva: “[...] Por outro lado, o livro 'Dona Flor e Seus Dois Maridos', de Jorge Amado, será lançado amanhã em Feira de Santana para onde seguirá uma caravana, levando também o desenhista Floriano Teixeira". (Notícia de redação, Jornal da Babia - Salvador, 20 jul. 1966).

O mesmo jornal, no mesmo dia, reforça o momento de autógrafos na "Livraria Pingo de Ouro", no dia 21 de julho, "[...] a convite de diversas entidades culturais" e confirma a presença da comitiva que, atendendo solicitação de Jorge Amado, deverá acompanhá-lo a Feira de Santana, acrescentando apenas o nome do cronista Giovanni Guimarães (colega e amigo do escritor), do Jornal $A$ Tarde, de Salvador.(Notícia de redação, Jornal da Babia - Salvador, 20 jul. 1966).

No dia da realização do lançamento da Livraria Pingo de Ouro, estouram notícias, tanto na capital do estado, como grande comentário em Feira.

O Diário de Notícias, de 21 de julho de 1966, traz duas notícias, ambas ligadas ao colunismo social: a de Sylvio Lamenha, na notícia anteriormente comentada, e a de Antônio José, intitulada "Jorge autografa na Supercity", ajuntando em seu estilo costumeiro:

Feira de Santana - Hoje, ao crepusculino momento feirense, o grande romancista baiano Jorge Amado - um dos expoentes máximos da Literatura Nacional, estará autografando na Livraria Lápis d'Ouro [sic] para toda Feira Cultural, Social, Econômica, Financeira \& Política a sua mais recente obra "Dona Flor e Seus Dois Maridos". (Antônio José, Diário de Notícias - Salvador, 21 jul. 1966).

Observo na notícia traços do estilo do colunismo da época: a valorização da localidade e a importância do evento, que envolve o setor cultural, o econômico, o financeiro e o político de Feira de Santana, agrupando os novos e os mais velhos de toda a comunidade. 
Encerrando seu noticiário, o colunista acrescenta, aos moldes de então e reafirmando sua missão de arauto:

Afinal, hoje o tão esperado Dia - D mais um Dia que comporá mais uma página da estremecida História de Feira de Santana. Será sem dúvida, o encontro da intelectualidade desta Planície Amada, pois todos os caminhos feirenses convergirão logo mais para a Livraria Lápis d'Ouro [sic], para receberem o autógrafo do Jorge Amado. (Antônio José, Diário de Notícias - Salvador, 21 jul. 1966).

A lembrança histórica do lendário "Dia D" é retomada como cúmplice para enaltecer tal "encontro da intelectualidade", pois, como escreve o jornalista, "todos os caminhos feirenses convergirão logo mais para" Livraria Lápis de Ouro, para Dona Flor e para Jorge Amado.

No mesmo dia 21 de julho, o Jornal da Babia estampa na coluna "Sociedade, fatos e gente", de Guilherme Simões, o lançamento da Lápis de Ouro do último livro amadiano, editado pela "Martins", de São Paulo. O deslocamento da caravana de amigos / intelectuais do autor é frisado:

A convite do romancista, integrarão a caravana vários intelectuais baianos, entre os quais os escritores Luís Henrique Dias Tavares e Guido Guerra, pintores Emanuel Araújo e Floriano Teixeira, livreiro Dmeval da Costa Chaves, cronista Giovani Guimarães e editores da Guillar que, atualmente, se encontram nesta capital. (Simões, Jornal da Babia - Salvador, 21 jul. 1966).

Mais uma vez, o escritor reúne, com sua habilidade política vivenciada, personalidades não apenas locais para acompanhá-lo ao evento feirense.

O Diário de Notícias, de 23 de julho de 1966, sob o título de "Sucesso de 'Dona Flor' em Feira", comenta o sucesso acontecido no lançamento da Lápis de Ouro e registra a presença do acompanhamento, ao tempo em que chama a atenção à acolhida dispensada aos visitantes: "A caravana que acompanhou Jorge Amado foi recepcionada na residência do professor Dival Pitombo, na chácara "Teixeira Moleque", do Deputado Rui Santos e do sr. Isaltino Chaves, tendo regressado por volta das 22 horas". (Notícia de redação, Diário de Notícias - Salvador, 23 jul. 1966).

Cumprindo tarefa memorialística, transcrevo o final da notícia divulgada pelo citado periódico, marcando a presença de vultos da sociedade feirense ao lançamento da Pingo de Ouro: 
Entre outras pessoas presentes, estiveram na tarde de autógrafos o professor Dival Pitombo e senhora, jornalista Kleber Alencar, dr. Carlos Kruchewsky, Prefeito Joselito Amorim, srs. Fernando Pinto, jornalista Antonio José, além do sr. Dmeval Chaves, da Civilização Brasileira e senhora, Norma Sampaio, Luiz Henrique, jornalistas Guido Guerra e Otacílio Fonseca, Manuel Cervino, da Editora Aguillar, Floriano Teixeira, Zélia Amado e Paloma Amado, que acompanharam o escritor. (Notícia de redação, Diário de Notícias - Salvador, 23 jul. 1966).

Encerrando as notícias sobre o lançamento da Pingo de Ouro, o periódico feirense Folha do Norte, de 23 de julho de 1966, anota a consagração do escritor Jorge Amado, pelo número de presenças e de aquisições de seu novo livro publicado: "Mais de trezentos volumes foram vendidos, atestando o prestígio do romancista em Feira de Santana”. (Notícia de redação, Folha do Norte - Feira de Santana, 23 jul. 1966).

Entre os presentes ao ato, a nota assinala os escritores Dival Pitombo e Eurico Alves Boaventura, os pintores Francisco Liberato, Juraci Dórea e Aderbal Moura, o ceneasta Olney São Paulo, os jornalistas Hélder Alencar, Raymundo Pinto, Eme Portugal, Antônio Álvaro, Luciano Ribeiro, além do professor José Maria Marques, um dos primeiros reitores da futura Universidade Estadual de Feira Santana.

Desse modo, Dona Flor chega às terras feirenses.

\section{$\operatorname{soc}$}

\section{REFERÊNCIAS}

ANTÔNIO JOSÉ. Informes de Antônio José. Diário de Notícias, Salvador, 16 jul. 1966. Caderno 2, p. 5. ANTÔNIO JOSÉ. Jorge autografa na Supercity. Diário de Noticias, Salvador, 21 jul. 1966. Caderno 2, p. 5. COHEN, Renato. Performance como linguagem: criação de um tempo-espaço de experimentação. São Paulo: Perspectiva: EDUSP, 1989.

CONDÉ, José. Escritores e livros. Correio da Manhã, Rio de Janeiro, 21 jun. 1966. Caderno 2, p. 2.

DÓREA, Juraci. O presépio sertanejo de Cristina dos Santos. In: Légua \& meia: Revista de literatura e diversidade cultural. Programa de Pós-Graduação em Literatura e Diversidade Cultural da Universidade Estadual de Feira de Santana. Feira de Santana: v. 3, nº 2, 2004. p. 101-114.

FERNANDES, Hélio. Fatos e rumores. Tribuna da Imprensa, Rio de Janeiro, 19 maio 1966. Caderno 1, p. 3. INSTITUTO BAIANO DE EXPANSÃ O CULTURAL. Perfil analitico dos municípios. Salvador: IBEC, 1974. JULI. Sociedade, p. 6. A Tarde, Salvador, 28 jul. 1966.

LAMENHA, Sylvio. HI-SO. Diário de Notícias, Salvador, 20 jul. 1966. Caderno 2, p. 3.

LAMENHA, Sylvio. HI-SO. Diário de Notícias, Salvador, 21 jul. 1966. Caderno 2, p. 3.

NOTÍCIA DE REDAÇÃO. Diário de Notícias, Salvador, 15 jul. 1966. Caderno 1, p. 6.

NOTÍCIA DE REDAÇÃO. Jorge Amado leva "Dona Flor" a Feira. Diário de Notícias, Salvador, 20 jul. 1966. Caderno 1, p. 4. 
NOTÍCIA DE REDAÇÃO. Corre um rio de lágrimas, p. 2. Jornal da Babia, Salvador, 20 jul. 1966.

NOTÍCIA DE REDAÇÃO. Dona Flor vai a Feira, p. 2. Jornal da Babia, Salvador, 20 jul. 1966.

NOTÍCIA DE REDAÇÃO. Sucesso de "Dona Flor" em Feira. Diário de Notícias, Salvador, 23 jul. 1966.

Caderno 1, p. 6.

NOTÍCIA DE REDAÇÃO. Tarde de autógrafos. Folha do Norte, Feira de Santana, 23 jul. 1966.

PADRE, Mario. Através do Brasil. (Diário de viagem). Rio de Janeiro: 1979.

POPPINO, Rollie E. Feira de Santana. Tradução Arquimedes Pereira Guimarães. Salvador: Itapuã, 1968.

SANTIAGO, Silviano. Uma literatura nos trópicos: ensaios sobre dependência cultural. 2. ed. Rio de Janeiro: Rocco, 2000.

SILVEIRA, Junot. Livros, p. 5. A Tarde, Salvador, 13 jul. 1966.

SIMÕES, Guilherme. Sociedade, fatos e gente, p. 2. Jornal da Babia, Salvador, 21 jul. 1966.

\section{Resumo}

O lançamento de Dona Flor e Seus Dois Maridos, de Jorge Amado, realizado na Livraria Lápis de Ouro, em Feira de Santana, no ano da estréia da narrativa, em 1966, utiliza os recursos da mídia local e os da capital do Estado da Bahia - o jornalismo, sobretudo, - no preparo, efetivação e registro do acontecimento. Por se tratar do primeiro ato de divulgação do livro fora das capitais brasileiras, outros lances são ainda ativados: o reconhecimento do autor da obra, o colorido da política municipal e a representatividade da liderança sócio-cultural da região presente ao ato, o que anteveria as possibilidades de desdobramentos intelectuais futuros da comunidade feirense.

\section{Abstract}

The release of Dona Flor and her two Husbands, by Jorge Amado, which took place at Livraria Lápis de Ouro, in Feira de Santana, in the year of the début of narrative, in 1966, uses the resources of local media and of the capital of the State of Bahia - journalism, above all - in the preparation, realization and register of the event. Since it was the first act of divulgence of the book outside Brazilian capitals, other things are done: the recognition of the author of the work, the color of the municipal politics and the representative members of the sociocultural leadership of the region who were present in the event, which would anticipate the possibilities of the future intellectual consequences in the Feirense community

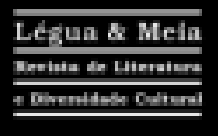

VEIGAN, Benedito. O lançamento da lápis de ouro ou Dona Flor e seus dois maridos chega a feira de santana. Légua \& meia: Revista de literatura e diversidade cultural. Feira de Santana: UEFS, v. 4, $\mathrm{n}^{\circ} 3,2005$, p. 212-222.

Benedito Veiga é baiano, Doutor em Letras e estudioso da obra de Jorge Amado, com ensaios e livros publicados. E professor da Pós-Graduação em Literatura e Diversidade Cultural e de Literatura Brasileira da UEFS, além de Professor Titular de Teoria da Literatura da UCSal. 